\title{
Survival of Patients with Lung Cancer in the Setting of Liver Cirrhosis: A Multicenter Propensity Score Matching Study
}

\author{
Ming-Shian Lu (D) \\ Hung-I Lu ${ }^{2}$ \\ Tzu-Ping Chen ${ }^{3}$ \\ Che-Chia Chang' \\ Tsung-Ming Yang (iD ${ }^{4}$ \\ Miao-Fen Chen ${ }^{5,6}$ \\ 'Division of Thoracic and Cardiovascular \\ Surgery, Chiayi Chang Gung Memorial \\ Hospital, Puzi, Chiayi County, Taiwan; \\ ${ }^{2}$ Division of Thoracic and Cardiovascular \\ Surgery, Kaohsiung Chang Gung \\ Memorial Hospital, Kaohsiung City, \\ Taiwan; ${ }^{3}$ Division of Thoracic and \\ Cardiovascular Surgery, Keelung Chang \\ Gung Memorial Hospital, Keelung City, \\ Taiwan; ${ }^{4}$ Division of Pulmonary and \\ Critical Care Medicine, Chiayi Chang \\ Gung Memorial Hospital, Puzi, Chiayi \\ County, Taiwan; ${ }^{5}$ Department of \\ Radiation Oncology, Chiayi Chang Gung \\ Memorial Hospital, Puzi, Chiayi County, \\ Taiwan; ${ }^{6}$ College of Medicine, Chang \\ Gung University, Taoyuan City, Taiwan
}

Purpose: The survival outcome of lung cancer patients with coexisting liver cirrhosis has thus far received limited attention in the literature. In this study, we evaluated whether liver cirrhosis is an independent risk factor for the survival of patients with lung cancer.

Materials and Methods: We conducted a retrospective, multicenter, propensity-matched study of lung cancer patients with and without liver cirrhosis. To determine differences in survival, we sought to identify risk factors associated with poor outcomes using KaplanMeier survival analysis and Cox proportional hazards regression.

Results: There were no statistically significant differences in the baseline clinical characteristics of patients between the cirrhosis and non-cirrhosis groups. The median overall survival of patients with and without cirrhosis was 13.07 months (95\% confidence interval [CI]: 10.56-16.84) and 13.67 months (95\% CI: 10.42-16.91), respectively ( $\mathrm{p}=0.76)$. Cox proportional hazards regression analysis revealed that liver cirrhosis was not an independent risk factor for poor outcome (hazard ratio [HR]: 1.057, 95\% CI: 0.805-1.388, p=0.690). In patients with cirrhosis, lower serum albumin levels, higher Charlson Comorbidity Index score, advanced-stage lung cancer, and treatment modality were factors associated with poor outcome. Increase in serum albumin by $1 \mathrm{~g}$ was associated with a $30 \%$ reduction in the risk of mortality (HR: $0.700,95 \%$ CI: $0.494-0.993, p=0.045$ ). While every point increase in the Charlson Comorbidity Index score by 1 point was linked to a $9 \%$ higher risk of mortality (HR: 1.090, 95\% CI: 1.023-1.161, p=0.007).

Conclusion: The survival rates of lung cancer patients with and without cirrhosis did not differ significantly. Higher serum albumin levels and lower Charlson Comorbidity Index scores were associated with improved survival.

Keywords: liver cirrhosis, lung neoplasm, outcome, survival

\section{Introduction}

Cancer, a leading cause of death worldwide, is an important public health concern. In 2020, the estimated new cases of lung cancer in men and women were 116,300 and 112,520 , respectively. ${ }^{1}$ Although lung cancer accounts for only $12.9 \%$ of newly diagnosed cancer cases, it is responsible for $23.5 \%$ of all cancer-related deaths; this percentage is higher than those associated with breast, colon, and prostate cancers combined. $^{2}$ Despite improvements in medical and surgical therapy, the overall 5 -year survival for patients with lung cancer is only $19.4 \%$, mainly due to the advanced stage of disease at diagnosis. Only $16.4 \%$ of lung cancer cases are localized and suitable for curative resection at the time of diagnosis. ${ }^{2}$ Surgical
Correspondence: Miao-Fen Chen Department of Radiation Oncology, Chiayi Chang Gung Memorial Hospital,

No. 6, Sec. West, Jiapu Road, Puzi City,

Chiayi County, 61363, Taiwan

Tel +8865362100 Ext 20II

Fax +88653623002

Email miaofen@cgmh.org.tw 
treatment currently offers the best chance for long-term survival in patients with early-stage lung cancer. Unfortunately, surgical resection is not suitable in some cases owing to existing comorbidities, such as liver cirrhosis. Liver cirrhosis (ie, irreversible fibrosis of the liver) is the 13th leading cause of years of life lost, only one place behind lung cancer. ${ }^{3}$ The 1 -year mortality rate associated with cirrhosis varies widely depending on clinical decompensation, ranging from $1 \%$ to $57 \%{ }^{4}$ Surgical stress is considered a possible decompensating event in patients with compensated liver cirrhosis. ${ }^{5}$ Research addressing the combination of these two conditions is limited and primarily consists of small surgical cases series. ${ }^{6-8}$ Since clinical investigations involving lung cancer patients with liver cirrhosis are scarce in the medical literature, we conducted a multicenter propensity score matching clinical study to evaluate outcomes in this setting.

\section{Materials and Methods}

The institutional review board of Chang Gung Memorial Hospital approved this clinical study and waived the requirement for individual informed consent due to its retrospective design. All obtained information was maintained confidential according to the ethical standards of the hospital and in compliance with the tenets of the Declaration of Helsinki.

We used the Chang Gung Memorial Hospital Cancer Registry to collect clinical data from three hospitals belonging to the Chang Gung Medical Foundation (Kaohsiung Chang Gung Hospital, Keelung Chang Gung Memorial Hospital, and Chiayi Chang Gung Memorial Hospital). In this study, we included all adult patients (aged $>18$ years) diagnosed with liver cirrhosis (International Classification of Diseases, 9th Revision (ICD-9), code: 571.2, 571.2, 571.9) and lung cancer (ICD-9, code: 162) from January 2007 to December 2012.

The etiology of liver cirrhosis was established according to standard criteria for infection with hepatitis B virus (positive serum test for hepatitis B surface antigen), hepatitis $\mathrm{C}$ virus (seropositivity for hepatitis $\mathrm{C}$ virus antibody), coinfection with hepatitis $\mathrm{B}$ and $\mathrm{C}$ viruses, alcoholism, or unknown. We used a combination of imaging examinations (ie, nodular, small, and shrunken liver, splenomegaly, and portosystemic collateral on ultrasonography, and/or computed tomography) in association with an abnormal serologic test, endoscopic evidence of esophageal varices, direct surgical inspection, or pathological examination.
Using propensity score matching based on age, sex, smoking status, histology, cancer stage, and treatment modality, patients with lung cancer and coexisting liver cirrhosis were matched (1:1) with lung cancer patients without liver cirrhosis. We collected the following information from the medical records: age at diagnosis of lung cancer, sex, smoking history, creatinine level, albumin level, Model for End-Stage Liver Disease (MELD) score, ${ }^{9}$ Child-Pugh Score, ${ }^{10}$ Charlson Comorbidity Index (CCI) ${ }^{11}$ lung cancer histology and stage at diagnosis, primary treatment (all treatment modalities administered within 3 months post diagnosis), and overall survival. For the Child-Pugh Score, the total score was used rather than the patients being divided into subgroups: class A (5-6 points); class B (7-9 points); and class C (10-15 points). For the CCI, we used the total scores from each morbidity score to determine potential associations with mortality. Lung cancer staging was performed according to the 7th edition of the TNM staging system. ${ }^{12}$ Overall survival was calculated from the day of pathological confirmation until the last follow-up or 31st December 2015. Typically, the case manager of the cancer center contacted the patients by telephone to follow up regarding their condition. Those not reachable by telephone and withdrawn from the National Health Insurance scheme were presumed dead. The National Health Insurance scheme of Taiwan offers universal coverage to $>99 \%$ of the population. Individuals are excluded from the National Health Insurance scheme only because of death, outstanding premium payments for $>6$ months, emigration, or change of nationality. For status update, the Health Promotion Administration, Ministry of Health and Welfare, Taiwan, releases an annual death report concerning all patients with cancer registered in each cancer center.

We collected all laboratory examination data from 3 months before diagnosis to the day of treatment initiation. In the final analysis, we used the data obtained at the closest date to that of diagnosis. Some patients had missing data for albumin levels $(\mathrm{n}=23,7.77 \%)$, international normalized ratio $(\mathrm{n}=22,7.43 \%)$, sodium levels $(\mathrm{n}=7,2.36 \%)$, and total bilirubin levels ( $n=21,7.09 \%)$. We analyzed the pattern of these missing data and classified them as missing at random; the multiple imputation technique (number of imputations: 5) was used to replace the missing values. ${ }^{13}$

\section{Statistical Analysis}

We simultaneously calculated the propensity score using logistic regression, with cirrhosis as the dependent 


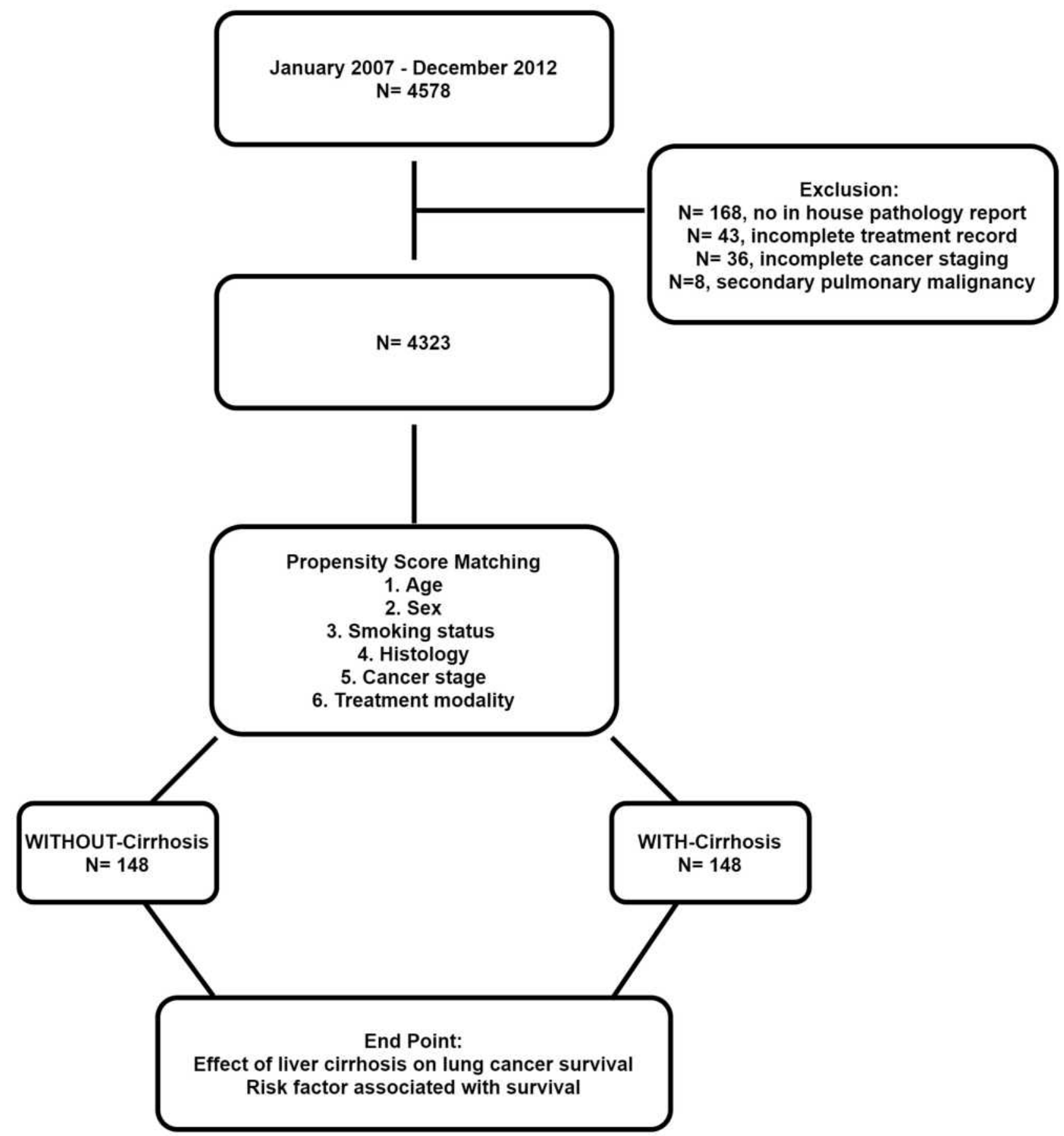

Figure I Patient selection and matching process.

variable, and propensity score matching to select control patients (ie, patients without cirrhosis) based on several confounders. ${ }^{14}$ We used a caliper width 0.2 -fold greater than the standard deviation of the propensity score without replacement to match patients with and without cirrhosis. ${ }^{15}$ Because of no normal distribution, continuous data are presented as the median \pm standard deviation and categorical data are presented as percentages. We used the chi-square or Fisher's exact test to analyze categorical variables (depending on the cell size) and analysis of variance for continuous variables. Clinical stages were classified into stages I-IIIA versus stages IIIB-IV. Treatment modalities were grouped into supportive treatment, surgical treatment (excluding diagnostic/staging 
Table I Demographic Characteristics of Lung Cancer Patients with and without Liver Cirrhosis

\begin{tabular}{|c|c|c|c|c|}
\hline Characteristic & Total (\%) & Non-Cirrhosis Group & Cirrhosis Group & p-value \\
\hline Number of patients & $296(100)$ & $148(50)$ & $148(50)$ & \\
\hline Age, years (median $\pm S D$ ) & $68 \pm 11.28$ & $68 \pm 10.91$ & $68 \pm 11.67$ & 0.75 \\
\hline Sex & & & & 0.88 \\
\hline Female & $58(19.5)$ & $30(10.1)$ & $28(9.4)$ & \\
\hline Male & $240(80.5)$ & $120(40.3)$ & $120(40.3)$ & \\
\hline Smoking history & & & & 0.91 \\
\hline No & $118(39.6)$ & $60(20.1)$ & $58(19.5)$ & \\
\hline Yes & $180(60.4)$ & $90(30.2)$ & $90(30.2)$ & \\
\hline Creatinine, in $\mathrm{mg} / \mathrm{dl}($ median $\pm \mathrm{SD})$ & $0.95 \pm 1.06$ & $0.91 \pm .0 .48$ & $0.98 \pm 1.42$ & 0.12 \\
\hline Albumin & $3.30 \pm 0.69$ & $3.40 \pm 0.66$ & $3.24 \pm 0.71$ & 0.006 \\
\hline Total bilirubin & $0.83 \pm 1.45$ & $0.75 \pm 1.4 \mathrm{I}$ & $0.90 \pm 1.50$ & 0.23 \\
\hline INR & $1.05 \pm 0.23$ & $1.01 \pm 0.21$ & $1.07 \pm 0.25$ & 0.057 \\
\hline Ascites (yes) & $13(4.4)$ & $\mathrm{I}(0.3)$ & $12(4.1)$ & 0.003 \\
\hline Encephalopathy (yes) & $28(9.5)$ & I (0.3) & $27(9.1)$ & $<0.001$ \\
\hline MELD score & $8 \pm 3.52$ & $7 \pm 3.43$ & $9 \pm 3.54$ & 0.006 \\
\hline Child-Pugh Score & $6 \pm 1.09$ & $6 \pm 1.03$ & $6 \pm 1.10$ & 0.001 \\
\hline Charlson Comorbidity Index score (median \pm SD) & $7 \pm 2.63$ & $7 \pm 2.61$ & $7 \pm 2.65$ & 0.117 \\
\hline Lung cancer stage & & & & 0.68 \\
\hline IA-IIIA & $87(28.2)$ & $36(12.1)$ & $48(16.1)$ & \\
\hline IA & $18(6)$ & $9(3)$ & $9(3)$ & \\
\hline IB & $26(8.7)$ & II (3.7) & $15(5)$ & \\
\hline IIA & $6(2.0)$ & $2(0.7)$ & $4(1.3)$ & \\
\hline IIB & $4(1.3)$ & $2(0.7)$ & $2(0.7)$ & \\
\hline IIIA & $30(10.1)$ & $12(4)$ & $18(6)$ & \\
\hline IIIB-IV & $214(71.8)$ & $114(38.3)$ & $100(33.6)$ & \\
\hline IIIB & $32(10.7)$ & $15(5)$ & $17(5.7)$ & \\
\hline IV & $182(61.1)$ & $99(33.2)$ & $83(27.9)$ & \\
\hline Histology & & & & 1.00 \\
\hline NSCLC & $263(88.3)$ & I $32(44.3)$ & $|3|(44)$ & \\
\hline SCLC & $35(11.7)$ & $18(6)$ & $17(5.7)$ & \\
\hline Treatment & & & & 0.58 \\
\hline No treatment/supportive care & $5 I(17.1)$ & $24(8.1)$ & $27(9.1)$ & \\
\hline Surgical treatment & $67(22.5)$ & $31(10.4)$ & $36(12.1)$ & \\
\hline OP & $35(11.7)$ & $16(5.4)$ & $19(6.4)$ & \\
\hline $\mathrm{OP}+\mathrm{CT}$ & $23(7.7)$ & $7(2.3)$ & $16(5.4)$ & \\
\hline $\mathrm{OP}+\mathrm{CT}+\mathrm{RT}$ & $4(1.3)$ & $3(1)$ & $\mathrm{I}(0.3)$ & \\
\hline OP+Target & $5(1.7)$ & $5(1.7)$ & $0(0)$ & \\
\hline Medical treatment & $180(60.4)$ & $95(31.9)$ & $85(28.5)$ & \\
\hline CT & $92(30.9)$ & $51(17.1)$ & $4 \mid(13.8)$ & \\
\hline $\mathrm{CT}+\mathrm{RT}$ & $37(12.4)$ & $16(5.4)$ & $21(7)$ & \\
\hline CT+Target & $6(2)$ & $5(1.7)$ & I $(0.3)$ & \\
\hline RT & $10(3.4)$ & $5(1.7)$ & $5(1.7)$ & \\
\hline RT+Target & $4(1.3)$ & $2(0.7)$ & $2(0.7)$ & \\
\hline Target & $30(10.1)$ & $15(5)$ & $15(5)$ & \\
\hline Cryotherapy & I (0.3) & I $(0.3)$ & $0(0)$ & \\
\hline
\end{tabular}

Notes: The Charlson Comorbidity Index score was calculated with the exclusion of liver cirrhosis.

Abbreviations: CT, chemotherapy; INR, international normalized ratio; MELD, Model for End-Stage Liver Disease; NSCLC, non-small cell lung cancer; OP, surgical resection; RT, radiotherapy; SCLC, small cell lung cancer; SD, standard deviation; Target, target therapy. 
Table 2 Etiology of Liver Cirrhosis

\begin{tabular}{|l|l|}
\hline & N (\%) \\
\hline Alcoholism & $38(25.67 \%)$ \\
\hline Hepatitis B virus & $42(28.38 \%)$ \\
\hline Hepatitis C virus & $41(27.70 \%)$ \\
\hline Hepatitis B and C viruses & $9(6.08 \%)$ \\
\hline Non-alcoholic fatty liver disease & $4(2.70 \%)$ \\
\hline Unknown & $14(9.46 \%)$ \\
\hline
\end{tabular}

procedure), and medical treatment. For survival analysis, we used the Kaplan-Meier method and the Log rank test to calculate differences in survival. Cox proportional hazards regression analysis was performed to estimate the level of significance and relative risk with a $95 \%$ confidence interval (CI). A p-value $<0.05$ denoted statistically significant difference. The clinical data were analyzed using the SPSS 21.0 software (IBM Corporation, Armonk, NY, USA).

\section{Results}

\section{Patient Selection}

During the study period, 4323 patients with lung cancer were included in the analysis and matched as described in the Methods section. Figure 1 shows the patient selection and matching process.

\section{Patient Characteristics}

Following the matching process, there was no statistically significant difference in the baseline clinical characteristics of patients. Table 1 presents the clinical characteristics of the cohort. Significant differences between patients with and without cirrhosis were observed in MELD score (9 \pm 3.54 vs $7 \pm 3.43$, respectively, $p=0.006$ ), Child-Pugh score $(6.00 \pm 1.10$ vs $6.00 \pm 1.03$, respectively, $\mathrm{p}=0.001)$, and serum albumin levels $(3.24 \pm 0.71$ vs $3.40 \pm 0.66$, respectively, $\mathrm{p}=0.006$ ). Patients with cirrhosis were more likely to present with ascites and encephalopathy versus those without cirrhosis (Table 1). The etiologies of liver cirrhosis were alcoholism $(\mathrm{n}=38,25.67 \%)$, infection with hepatitis $B$ virus $(n=42,28.38)$, infection with hepatitis $C$ virus $(\mathrm{n}=41,27.70 \%)$, coinfection with hepatitis $\mathrm{B}$ and $\mathrm{C}(\mathrm{n}=9$, $6.08 \%)$, non-alcoholic fatty liver disease $(n=4,2.70 \%)$, and unknown ( $\mathrm{n}=14,9.46 \%)$ (Table 2). The distribution of histological types according to the stages of lung cancer for patients with and without cirrhosis is displayed in Table 3. The most common histological type was adenocarcinoma, followed by squamous cell carcinoma.

\section{Survival Outcome of Lung Cancer Patients with and without Cirrhosis}

Kaplan-Meier survival analysis did not reveal a statistically significant difference in survival between patients with and without cirrhosis (Figure 2). The median overall survival of patients with and without cirrhosis was 13.07 months (95\% CI: 10.56-16.84) and 13.67 months (95\% CI: 10.42-16.91), respectively $(\mathrm{p}=0.76)$ (Figure 2 ).

Cox proportional hazards regression analysis revealed that serum albumin levels, CCI score, advanced-stage lung cancer, and treatment modality were independent factors associated with poor outcome for patients with cirrhosis (Table 4). Increase in serum albumin by $1 \mathrm{~g}$ was associated with a $30 \%$ reduction in the risk of mortality (hazard ratio [HR]: $0.700,95 \%$ CI: 0.494-0.993, $p=0.045$ ). Increase in the CCI score by 1 point was linked to a $9 \%$ higher risk of mortality (HR: 1.090, 95\% CI: 1.023-1.161, p=0.007). A significant difference in survival was observed

Table 3 Distribution of Cancer Histology According to Cancer Stage

\begin{tabular}{|l|l|l|l|l|}
\hline & \multicolumn{2}{|c|}{ Without Cirrhosis (N) } & \multicolumn{2}{c|}{ With Cirrhosis (N) } \\
\hline Histological Type (N, \%) & Stage IA-IIIA & Stage IIIB-IV & Stage IA-IIIA & Stage IIIB-IV \\
\hline NSCLC (26I, 88.2\%) & 34 & 96 & 46 & 85 \\
Adenocarcinoma & 22 & 59 & 27 & 46 \\
Squamous cell carcinoma & 8 & 22 & 10 & 24 \\
Adenosquamous cell carcinoma & 1 & 4 & 5 & 6 \\
Large cell carcinoma & 0 & 3 & 0 & 2 \\
Sarcomatoid carcinoma & 3 & 1 & 4 & 1 \\
Non-small cell carcinoma & 0 & 7 & 0 & 6 \\
SCLC (35, II.8\%) & 1 & 17 & 2 & 15 \\
\hline
\end{tabular}

Abbreviations: NSCLC, non-small cell lung cancer; SCLC, small cell lung cancer. 


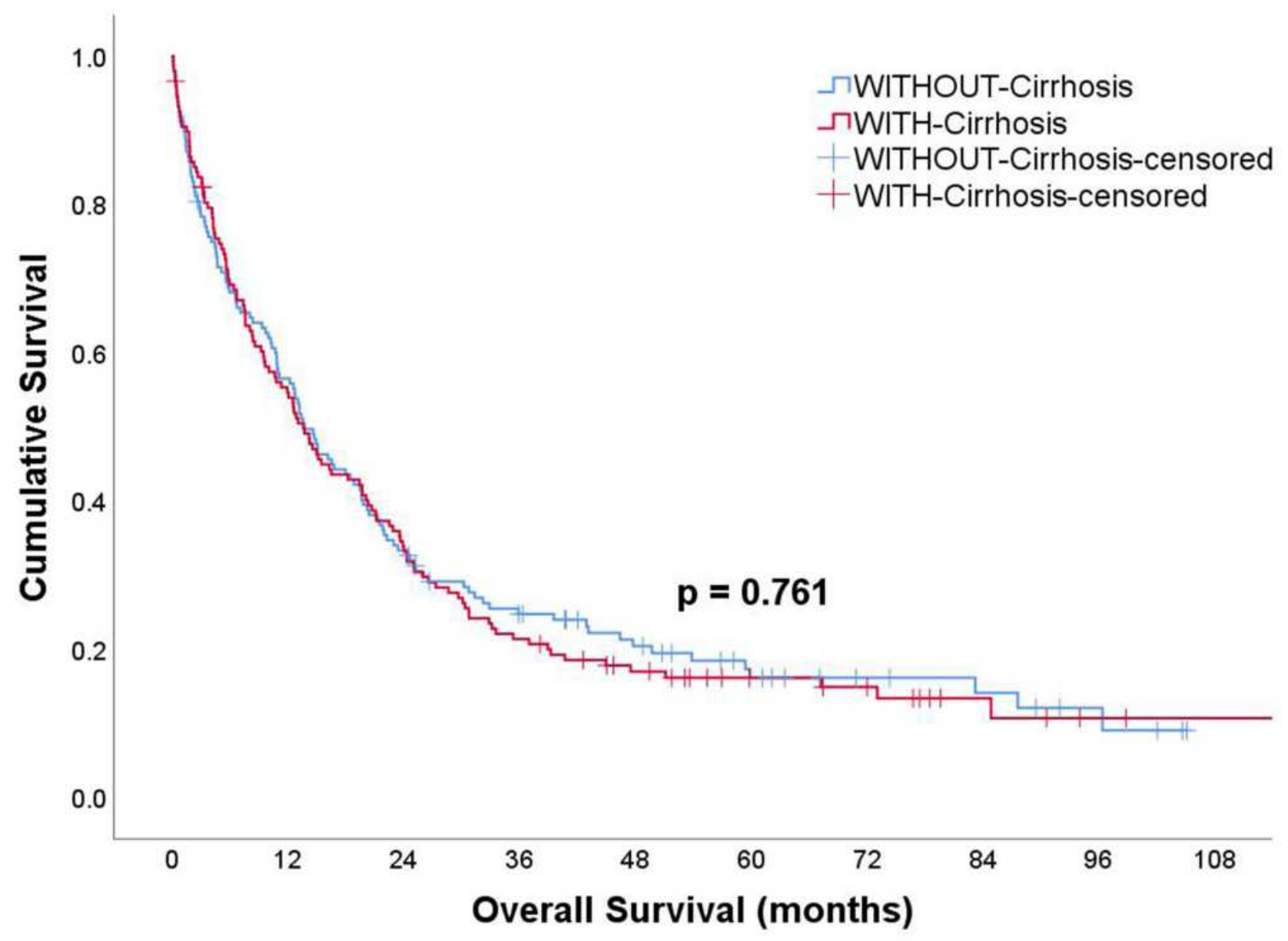

Figure 2 Survival curve for lung cancer patients with and without cirrhosis. There was no statistically significant difference in survival for WITH-Cirrhosis and WITHOUTCirrhosis lung cancer patients. The median overall survival for patients WITH-Cirrhosis was 13.07 months $(95 \% \mathrm{Cl} 10.56-16.84)$ compared to 13.67 months (95\% $\mathrm{Cl}$ |0.42-16.9|) for patients WITHOUT-Cirrhosis, $p=0.76$.

depending on the treatment modality. Using medical treatment as a reference, surgical treatment improved the chance of survival by $50 \%$ (HR: $0.502,95 \%$ CI: $0.288-$ $0.874, \mathrm{p}=0.015$ ).

\section{Discussion}

Cirrhosis is the consequence of damage to the liver induced by various etiologies. The most common causes are alcoholism, infection with hepatitis virus, and nonalcoholic fatty liver disease. ${ }^{16}$ Hepatitis $\mathrm{B}$ and $\mathrm{C}$ viruses are endemic in Taiwan; ${ }^{17}$ as expected, the most common cause of liver cirrhosis in Taiwan is infection with hepatitis B virus, followed by infection with hepatitis C virus. ${ }^{18-20}$ Consistent with previous reports, in this study, the main causes of liver cirrhosis were infections with hepatitis $\mathrm{B}$ and $\mathrm{C}$ viruses, followed by alcoholism and non-alcoholic fatty liver disease (Table 2).
Population-based studies have demonstrated that patients with liver cirrhosis are at an increased risk of developing lung cancer. ${ }^{21,22}$ Unfortunately, limited research has been conducted thus far to investigate this association. Only a few studies have assessed the survival outcome of these patients in detail. According to our analysis, the median overall survival of patients with and without cirrhosis was 13.67 months (95\% CI: $10.42-$ $16.91)$ and 13.07 months (95\% CI: 10.56-16.84), respectively $(\mathrm{p}=0.76)$. The 5 -year survival rate was $18.24 \%$ and $19.58 \%$, respectively. This is consistent with the results of a study conducted by Chiang et al, ${ }^{23}$ in which the 5 -year survival rate of patients with lung cancer in Taiwan was $16.3 \%$.

Traditionally, the Child-Pugh classification ${ }^{10}$ and MELD score $^{9}$ are the most frequently used tools to determine the degree of liver function impairment. In this cohort, patients with cirrhosis showed higher values for 
Table 4 Adjusted Cox Proportional Hazards Regression Analysis for Survival

\begin{tabular}{|c|c|c|c|}
\hline & $\begin{array}{l}\text { Adjusted } \\
\text { Hazard Ratio }\end{array}$ & $95 \% \mathrm{Cl}$ & p-value \\
\hline \multicolumn{4}{|l|}{ Liver cirrhosis } \\
\hline No & Ref & & \\
\hline Yes & 1.057 & $0.805-1.388$ & 0.690 \\
\hline Age & 1.001 & $0.988-1.014$ & 0.901 \\
\hline \multicolumn{4}{|l|}{ Sex } \\
\hline Female & Ref & & \\
\hline Male & 0.878 & $0.573-1.346$ & 0.550 \\
\hline \multicolumn{4}{|l|}{ Smoking history } \\
\hline No & Ref & & \\
\hline Yes & 1.113 & $0.797-1.554$ & 0.529 \\
\hline Creatinine & 1.076 & $0.907-1.277$ & 0.400 \\
\hline Albumin & 0.700 & $0.494-0.993$ & 0.045 \\
\hline Total bilirubin & 0.983 & $0.862-1.121$ & 0.799 \\
\hline INR & 1.645 & $0.84 I-3.217$ & 0.146 \\
\hline \multicolumn{4}{|l|}{ Ascites } \\
\hline No & Ref & & \\
\hline Yes & 0.933 & $0.430-2.026$ & 0.862 \\
\hline \multicolumn{4}{|l|}{ Encephalopathy } \\
\hline No & Ref & & \\
\hline Yes & 0.947 & $0.502-1.787$ & 0.866 \\
\hline MELD score & 1.021 & $0.958-1.088$ & 0.530 \\
\hline Child-Pugh Score & 1.083 & $0.838-1.398$ & 0.543 \\
\hline $\begin{array}{l}\text { Charlson Comorbidity } \\
\text { Index score }\end{array}$ & 1.090 & $1.023-1.161$ & 0.007 \\
\hline \multicolumn{4}{|l|}{ Stage } \\
\hline IA-IIIA & Ref & & \\
\hline IIIB-IV & 0.607 & $0.390-0.944$ & 0.027 \\
\hline \multicolumn{4}{|l|}{ Histology } \\
\hline NSCLC & Ref & & \\
\hline SCLC & 0.748 & $0.504-1.109$ & 0.149 \\
\hline \multicolumn{4}{|l|}{ Treatment } \\
\hline Supportive & 1.737 & $1.204-2.505$ & 0.003 \\
\hline Medical & Ref & & \\
\hline Surgical & 0.502 & $0.288-0.874$ & 0.015 \\
\hline
\end{tabular}

Notes: The Charlson Comorbidity Index score was calculated with the exclusion of liver cirrhosis. Serum albumin level, Charlson Comorbidity Index score, advanced-stage lung cancer, and treatment modality were independent factors associated with poor outcomes in patients for with cirrhosis. Increase in serum albumin by I $g$ was associated with a $30 \%$ reduction in the risk of mortality (HR: 0.700, 95\% Cl: 0.494-0.993, $\mathrm{p}=0.045)$. Increase in the Charlson Comorbidity Index score by I point was linked to a $9 \%$ higher risk of mortality (HR: $1.090,95 \% \mathrm{Cl}$ : I.023-I.16I, $\mathrm{p}=0.007)$. Using medical treatment as a reference, surgical treatment improved the chance of survival by $50 \%$ (HR: $0.502,95 \% \mathrm{Cl}: 0.288-0.874, p=0.015)$ Abbreviations: $\mathrm{Cl}$, confidence interval; HR, hazard ratio; INR, international normalized ratio; MELD, Model for End-Stage Liver Disease; NSCLC, non-small cell lung cancer; SCLC, small cell lung cancer. these two indices than those without cirrhosis: MELD (9 \pm 3.54 vs $7 \pm 3.43$, respectively, $\mathrm{p}=0.006$ ) and Child-Pugh score $(6 \pm 1.10$ vs $6 \pm 1.03$, respectively, $\mathrm{p}=0.001)$. The Child-Pugh classification includes five variables namely grade of encephalopathy and ascites, serum albumin levels, bilirubin levels, and prothrombin time, and international normalized ratio. In the present study, Cox proportional hazards regression analysis demonstrated that the Child-Pugh and MELD scores were not associated with poor outcome. However, independent examination of the components of the Child-Pugh classification revealed that higher serum albumin levels were associated with improved survival. As expected, patients with cirrhosis had lower serum albumin levels than those without cirrhosis $(3.24 \pm 0.71$ vs $3.40 \pm 0.66$, respectively, $\mathrm{p}=0.006)$. The multivariate analysis showed that an increase in serum albumin by $1 \mathrm{~g}$ reduced the risk of mortality by $30 \%$ (HR: $0.700,95 \%$ CI: $0.494-0.993, p=0.045$ ). This effect may be related to the functions of serum albumin beyond its vascular expander property. These include solubilization, transport, and metabolism of several substances, endothelial stabilization, homeostatic effect, antioxidant effect, and immunomodulation. ${ }^{24}$ Long-term administration of albumin in patients with cirrhosis was associated with improved management of ascites, spontaneous bacterial peritonitis, renal dysfunction, and severe hepatic encephalopathy. ${ }^{25}$ The therapeutic benefit of long-term administration of albumin in lung cancer patients with cirrhosis deserves further evaluation.

Lung cancer is a condition that typically affects elderly patients. The presence of multiple and severe comorbidities in elderly patients negatively affects overall survival. In this report, the CCI score in lung cancer patients with and without cirrhosis was $7 \pm 2.61$ and $7 \pm 2.65$, respectively (after excluding the 3 points for cirrhosis) $(\mathrm{p}=0.117)$. Morishima et $\mathrm{al}^{26}$ reported that increase in the CCI score by 1 point was linked to a higher risk (14\%) of all-cause mortality (HR: 1.14, 95\% CI: 1.04-1.24). In the Liverpool Lung Project, ${ }^{27}$ the severity of comorbidities increased the risk of lung cancer-specific mortality. In this study, the CCI score (used to assess the comorbidities) was an independent risk factor for poor outcome. In line with previous reports, increase in the CCI score by 1 point was associated with a $9 \%$ higher risk of mortality (HR: $1.090,95 \%$ CI: $1.023-1.161, p=0.007){ }^{26,27}$ 
Despite the expansion in the armamentarium for the treatment of lung cancer, surgical resection remains the best treatment option for long-term survival. In this study, the resection rate in lung cancer patients with cirrhosis was $24.32 \%$. This is consistent with the results of a study performed by Wang et $\mathrm{al}^{28}$ which reported a surgical resection rate of $31.78 \%$ in Taiwan. Several small clinical series assessing the surgical outcome of lung resection for patients with cirrhosis demonstrated acceptable surgical risk and long-term outcome. ${ }^{6-8}$ In a series of 17 patients from $\operatorname{Japan}^{6}$ (pneumonectomies: 3; lobectomies: 11; and wedge resection: 3 ), the 5 -year survival rate was $45.6 \%$. In the present cohort, the median overall survival of patients with and without cirrhosis who underwent surgery was 45.01 months (95\% CI: 10.55-79.47) and 87.65 months (95\% CI: $53.20-122.11)$, respectively $(\mathrm{p}=0.15)$; the 5 -year survival rate was $47.2 \%$ and $64.5 \%$, respectively.

The retrospective design of this study, the lack of histological grading, genetic examination, treatment summary (eg, possible reduction in the dose of chemotherapeutic drugs, toxicity), and the completion rate of the treatment are just examples of the existing limitations. Furthermore, all patients included in this analysis were Chinese; hence, caution should be exercised when generalizing the present findings to other ethnic groups.

\section{Conclusion}

Based on the present investigation, there is no significant difference in the survival of lung cancer patients with and without liver cirrhosis. For patients with adequate physical performance, surgical resection continues to be the preferred treatment option with regard to long-term survival.

\section{Acknowledgments}

The authors thank all members of the Cancer Center at Linkou Chang Gung Hospital, Kaohsiung Chang Gung Hospital, Keelung Chang Gung Memorial Hospital, and Chiayi Chang Gung Memorial Hospital for their invaluable help.

\section{Disclosure}

The authors have no conflicts of interest to report in this work.

\section{References}

1. Siegel RL, Miller KD, Jemal A. Cancer statistics, 2020. CA Cancer J Clin. 2020;70(1):7-30. doi:10.3322/caac.21590
2. Howlader N, Noone AM, Krapcho M, et al. SEER cancer statistics review, 1975-2017. Bethesda, MD: National Cancer Institute. Based on November 2019 SEER data submission, posted to the SEER web site; April, 2020. Available from: https://seer.cancer.gov/csr/1975_ 2017/. Accessed May 19, 2021.

3. GBD 2017 Causes of Death Collaborators. Global, regional, and national age-sex-specific mortality for 282 causes of death in 195 countries and territories, 1980-2017: a systematic analysis for the Global Burden of Disease Study 2017. Lancet. 2018;392:1736-1788.

4. D'Amico G, Garcia-Tsao G, Pagliaro L. Natural history, and prognostic indicators of survival in cirrhosis: a systematic review of 118 studies. J Hepatol. 2006;44:217-231. doi:10.1016/j.jhep.2005.10.013

5. Tsochatzis EA, Bosch J, Burroughs AK. Liver cirrhosis. Lancet. 2014;383(9930):1749-1761. doi:10.1016/S0140-6736(14)60121-5

6. Iwasaki A, Shirakusa T, Okabayashi K, et al. Lung cancer surgery in patients with liver cirrhosis. Ann Thorac Surg. 2006;82:1027-1032. doi:10.1016/j.athoracsur.2006.04.083

7. Iwata $\mathrm{T}$, Inoue K, Nishiyama N, et al. Long-term outcome of surgical treatment for non-small cell lung cancer with comorbid liver cirrhosis. Ann Thorac Surg. 2007;84:1810-1817. doi:10.1016/j. athoracsur.2007.07.030

8. Rivera C, Chevalier B, Fabre E, et al. Chirurgie du cancer du poumon chez le cirrhotique [Lung cancer surgery and cirrhosis]. Rev Pneumol Clin. 2015;71:12-19. French. doi:10.1016/j.pneumo.2014.09.006

9. Kamath PS, Wiesner RH, Malinchoc M, et al. A model to predict survival in patients with end-stage liver disease. Hepatology. 2001;33 (2):464-470. doi:10.1053/jhep.2001.22172

10. Pugh RN, Murray-Lyon IM, Dawson JL, Pietroni MC, Williams R. Transection of the oesophagus for bleeding oesophageal varices. $\mathrm{Br}$ J Surg. 1973;60:646-649. doi:10.1002/bjs. 1800600817

11. Charlson ME, Pompei P, Ales KL, MacKenzie CR. A new method of classifying prognostic comorbidity in longitudinal studies: development and validation. J Chronic Dis. 1987;40:373-383. doi:10.1016/ 0021-9681(87)90171-8

12. Goldstraw P, Crowley J, Chansky K, et al.; International Association for the Study of Lung Cancer International Staging Committee; Participating Institutions. The IASLC Lung Cancer Staging Project: proposals for the revision of the TNM stage groupings in the forthcoming (seventh) edition of the TNM classification of malignant tumours. $J$ Thorac Oncol. 2007;2(8):706-714. doi:10.1097/ JTO.0b013e31812f3c1a

13. Allison PD. Missing Data (Quantitative Application in the Social Sciences). Thousand Oaks (CA): Sage; 2002.

14. Rubin DB. Estimating causal effects from large data sets using propensity scores. Ann Intern Med. 1997;127:757-763. doi:10.7326/ 0003-4819-127-8_Part_2-199710151-00064

15. Austin PC. Optimal caliper widths for propensity-score matching when estimating differences in means and differences in proportions in observational studies. Pharm Stat. 2011;10:150-161. doi:10.1002/ pst. 433

16. Zhou WC, Zhang QB, Qiao L. Pathogenesis of liver cirrhosis. World J Gastroenterol. 2014;20:7312-7324. doi:10.3748/wjg.v20.i23.7312

17. Chen DS. From hepatitis to hepatoma: lessons from type B viral hepatitis. Science. 1993;262:369-370. doi:10.1126/science.8211155

18. Chen YC, Chu CM, Yeh CT, Liaw YF. Natural course following the onset of cirrhosis in patients with chronic hepatitis B: a long-term follow-up study. Hepatol Int. 2007;1:267-1273. doi:10.1007/s12072007-5001-0

19. Dai CY, Ho CK, Huang JF, et al. Hepatitis C virus viremia and low platelet count: a study in a hepatitis B \& $\mathrm{C}$ endemic area in Taiwan. $J$ Hepatol. 2010;52:160-166. doi:10.1016/j.jhep.2009.11.017

20. Lu SN, Su WW, Yang SS, et al. Secular trends and geographic variations of hepatitis B virus and hepatitis $\mathrm{C}$ virus-associated hepatocellular carcinoma in Taiwan. Int J Cancer. 2006;119:1946-1952. doi:10.1002/ijc. 22045 
21. Kalaitzakis E, Gunnarsdottir SA, Josefsson A, Björnsson E. Increased risk for malignant neoplasms among patients with cirrhosis. Clin Gastroenterol Hepatol. 2011;9:168-174. doi:10.1016/j.cgh.2010.10.014

22. Sorensen HT, Friis S, Olsen JH, et al. Risk of liver and other types of cancer in patients with cirrhosis: a nationwide cohort study in Denmark. Hepatology. 1998;28:921-925. doi:10.1002/ hep.510280404

23. Chiang CJ, Lo WC, Yang YW, You SL, Chen CJ, Lai MS. Incidence and survival of adult cancer patients in Taiwan, 2002-2012. J Formos Med Assoc. 2016;115:1076-1088. doi:10.1016/j.jfma.2015.10.011

24. Garcia-Martinez R, Caraceni P, Bernardi M, Gines P, Arroyo V, Jalan R. Albumin: pathophysiologic basis of its role in the treatment of cirrhosis and its complications. Hepatology. 2013;58:1836-1846. doi:10.1002/hep. 26338
25. Caraceni P, Riggio O, Angeli P, et al.; ANSWER Study Investigators. Long-term albumin administration in decompensated cirrhosis (ANSWER): an open-label randomized trial. Lancet. 2018;391:2417-2429. doi:10.1016/S0140-6736(18)30840-7

26. Morishima T, Matsumoto Y, Koeda N, et al. Impact of comorbidities on survival in gastric, colorectal, and lung cancer patients. J Epidemiol. 2019;29(3):110-115. doi:10.2188/jea.JE20170241

27. Marcus MW, Chen Y, Duffy SW, Field JK. Impact of comorbidity on lung cancer mortality - a report from the Liverpool Lung Project. Oncol Lett. 2015;9(4):1902-1906. doi:10.3892/ol.2015.2916

28. Wang BY, Huang JY, Chen HC, et al. The comparison between adenocarcinoma and squamous cell carcinoma in lung cancer patients. J Cancer Res Clin Oncol. 2020;146:43-52. doi:10.1007/ s00432-019-03079-8

\section{Publish your work in this journal}

Cancer Management and Research is an international, peer-reviewed open access journal focusing on cancer research and the optimal use of preventative and integrated treatment interventions to achieve improved outcomes, enhanced survival and quality of life for the cancer patient.
The manuscript management system is completely online and includes a very quick and fair peer-review system, which is all easy to use. Visit http://www.dovepress.com/testimonials.php to read real quotes from published authors. 